\title{
The nutritional and metabolic roles of selenium and vitamin $E$
}

\author{
By A. T. Diplock, Department of Biochemistry, Royal Free Hospital School of \\ Medicine, University of London, 8 Hunter Street, London $W C_{\text {I }} N$ I $B P$
}

\section{Introduction}

(a) Historical. The pioneering work of Herbert M. Evans and his associates that led in 1922 to the discovery of vitamin $\mathrm{E}$ was fittingly marked in $\mathrm{r} 962$ by a symposium in honour of Professor Evans. The resulting series of papers (Karrer, I 962) provides an excellent critical review of research on vitamin $\mathrm{E}$ up to that time. However, certain observations must be regarded as milestones in the often tortuous history of research on vitamin $\mathrm{E}$, and these require brief mention here: (I) the recognition of the nutritional relationship between dietary polyunsaturated fatty acids (PUFA) and vitamin E (Mattill, 1927; Mattill \& Golumbic, 1942); (2) the discovery that certain unphysiological antioxidants had vitamin $\mathbf{E}$ activity (Dam, r953); (3) the observation that selenium was an essential trace element whose function was intimately linked with that of vitamin E (Schwarz, I95 I).

(b) The antioxidant hypothesis. Arising as a direct consequence of the first two observations mentioned above, the first attempt to provide a hypothesis that explains the function of vitamin $\mathrm{E}$ and its nutritional inter-relationships was the antioxidant hypothesis (Horwitt, 196r; Tappel, I962). The biological function of $\alpha$-tocopherol was considered to be that of a lipid antioxidant and free-radical scavenger, and the varied spectrum of vitamin $E$ deficiency diseases was thought to be a consequence of non-specific tissue damage by free-radical species produced as a consequence of lipid peroxidation. Se, however, was something of an embarrassment to the hypothesis, because of the very low dietary amounts that were involved (of the order of $0.05 \mathrm{mg} / \mathrm{kg}$ ) in the prevention of disease, and attempts (e.g. Tappel, 1962) to attribute an antioxidant role to Se compounds were never quite convincing. In a critical and detailed study of the antioxidant hypothesis, Green and co-workers (e.g. Green, Diplock, Bunyan, McHale \& Muthy, 1967 ; Diplock, Bunyan, McHale \& Green, 1967; Green, Diplock, Bunyan, Muthy \& McHale, 1967) could find little evidence that PUFA-exacerbated vitamin $E$ deficiency was accompanied by increased destruction of ${ }^{14} \mathrm{C}$-labelled $\alpha$-tocopherol, or by accumulation of lipid peroxides, the two criteria that had come to be regarded as implicit in the hypothesis. In a review of this work, Green \& Bunyan (1969) concluded that the results were 'contrary to the requirements of the theory'.

\section{Selenoproteins}

(a) Glutathione peroxidase. The antioxidant hypothesis has recently received great impetus from the discovery that the glutathione peroxidase (GSH peroxidase) 
of rat erythrocytes is a selenoenzyme (Rotruck, Pope, Ganther, Swanson, Hafeman $\&$ Hoekstra, 1973). The function of GSH peroxidase in erythrocytes is to prevent oxidative haemolysis of the erythrocyte membrane by hydrogen peroxide (Mills, r959); the enzyme participates in a cyclical series of reactions as follows:

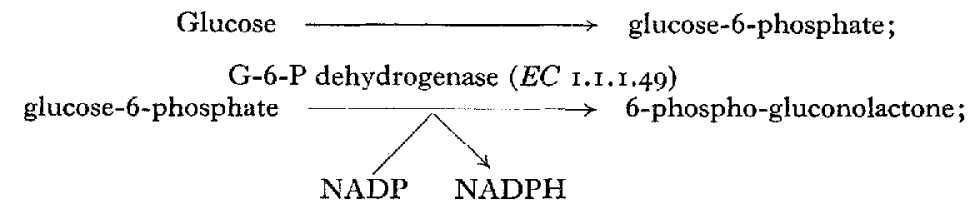

oxidized glutathione (GSSG)

glutathione reductase $(E C, \quad 1,6.4,2)$

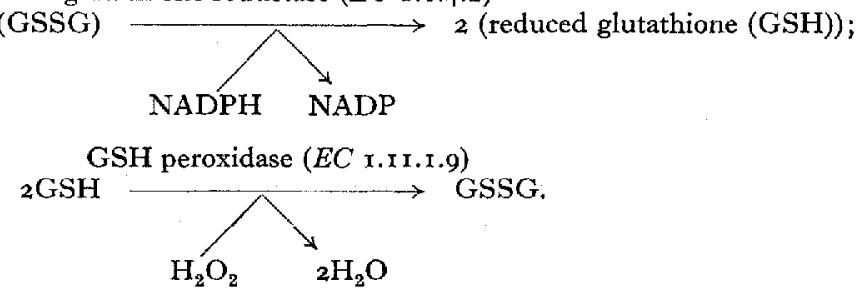

It has further been suggested that lipid peroxide may act as a substrate for the peroxidase enzyme (Hoekstra, I974). When erythrocytes from animals given ${ }^{75}$ Se were studied (Rotruck et al. I973) it was found that approximately $60 \%$ of the erythrocyte ${ }^{75} \mathrm{Se}$ was located in an enriched fraction containing the GSH peroxidase activity. Shortly afterwards, Flohé and co-workers showed that crystalline bovine GSH peroxidase contained $4 \mathrm{~g}$ atom Se/mol enzyme, as determined by neutron activation analysis (Flohé, Günzler \& Schock, 1973). They further concluded that the native enzyme (molecular weight 84000 ), which is known to contain four subunits, probably contains $\mathrm{I} g$ atom $\mathrm{Se}$ in each subunit.

Scott and co-workers have examined the relationship of Se and GSH peroxidase in the prevention of exudative diathesis in the chick (Noguchi, Cantor \& Scott, I973). They found, using a crystalline amino acid diet containing very small amounts of vitamin $\mathrm{E}$ and $\mathrm{Se}$, that the GSH peroxidase level of chick plasma is directly related to the Se level in the diet and to the effectiveness of Se in preventing exudative diathesis. Their results are interpreted by supposing that plasma GSH peroxidase may act by destroying peroxides that may be found in the plasma or cytosol of capillary cells, while vitamin $\mathrm{E}$ is thought to act by neutralizing free radicals within the capillary cell membranes. More recently Smith, Tappel \& Chow (1974) have studied the relationship between dietary Se and GSH peroxidase activity in seven tissues of the rat. They found a close correlation between dietary Se level, over a range of amounts from 0.005 to $2.0 \mathrm{mg} / \mathrm{kg}$, and the specific activity of GSH peroxidase; the dietary Se was given as selenomethionine.

Thus, there remains no doubt that Se is an important constituent of GSH peroxidase in three different species. The relationship of the function of this enzyme to that of vitamin $\mathrm{E}$ is still unclear, although it seems likely that the hypothesis proposed by Scott (Noguchi et al. 1973) may prove to be correct. At the present time, however, experimental evidence for these inter-relationships is lacking. 
(b) Other selenoproteins. It appears probable that other functions, unrelated to that of GSH peroxidase, may be found for Se in mammalian and avian tissues. Thus, considerable interest has been aroused by the work of the group at Oregon State University who have isolated a selenoprotein from the heart and semitendinosus muscles of lambs given Se in their diet. While the muscles of lambs given little dietary Se contain none of this protein, it is obtained from muscles of normal animals (Pedersen, Whanger, Weswig \& Muth, I972; Whanger, Pedersen \& Weswig, 1973). Following injection of $\left[{ }^{75} \mathrm{Se}\right]$ selenite, the protein was isolated from muscle homogenates by standard protein fractionation techniques. It has a molecular weight of about 10000 and physical measurements indicated a marked resemblance to the physical properties of cytochrome $c$. It was tentatively suggested (Whanger et al. 1973) that the protein might be a Se-containing cytochrome. The biological function of this protein is at present unknown but its properties suggest that it may participate in oxidation-reduction reactions.

Although not directly relevant here, it is of interest to mention two selenoproteins that have been discovered in bacteria. The ability of Escherichia coli to metabolize formate was found to be dependent on the availability of Se (Lester \& De Moss, 1971) and it was subsequently shown that a protein fraction containing formate dehydrogenase activity also contained ${ }^{75} \mathrm{Se}$ derived from the medium (Shum \& Murphy, 1972). Studies of the glycine reductase system of Clostridium sticklandii have also indicated that a selenoprotein component was involved. This protein, called protein $A$, is a heat-stable acidic protein with a molecular weight of about 12000 and has been obtained in pure form; it appears to contain $\mathrm{I} g$ atom $\mathrm{Se} / \mathrm{mol}$ (Turner \& Stadtman, 1973). Thus, in bacteria as well as in mammals and birds Se appears to have a function in, or proximal to, oxidation-reduction systems.

\section{Studies on vitamin $E$ and Se in the rat}

Work in our laboratory during the past 6 years has led to the development of a hypothesis (Diplock \& Lucy, I973) that is complementary to that of Scott (Noguchi et al. 1973).

(a) Studies on the oxidation state of Se. When ${ }^{75} \mathrm{Se}$ as $\mathrm{Na}_{2} \mathrm{SeO}_{3}$ was administered to rats under different nutritional conditions (Diplock, Baum \& Lucy, I97I) it was found that, when liver subcellular organelles were examined, a part of the ${ }^{75} \mathrm{Se}$ remained as $\mathrm{SeO}_{3}{ }^{2-}$, a part became oxidized and a part was apparently reduced to a form that was acid-volatile. The acid-volatile Se was susceptible to oxidation in vitro, and the amount present was directly related to the vitamin $\mathrm{E}$ level in the diet of the animals, so that treatment of vitamin E-deficient rats with $\alpha$-tocopherol resulted in an increase in the amount of acid-volatile Se. Further experiments (Diplock, Caygill, Jeffery \& Thomas, 1973) established that the acid-volatile Se was selenide and the proposal was made that a common pathway is responsible for the conversion of toxic amounts of Se to the volatile excretory product dimethyl selenide, and of trace amounts of Se to the oxidant-labile, protein-bound selenide of rat liver subcellular organelles. 
(b) Intracellular distribution of Se. Because the methods used for liver subcellular fractionation in the earlier experiments (Diplock et al. 1971) were subject to contamination from fraction to fraction, a method was devised for the complete fractionation of rat liver which was reproducible and gave a high degree of resolution of one fraction from another (Caygill, Lucy \& Diplock, 197I). In adequately fed rats, Se and particularly selenide were found to be strikingly localized in the mitochondria and smooth endoplasmic reticulum. The selenide was membrane-bound and, when vitamin $\mathrm{E}$ was removed from the diet given to the rats, the association with mitochondria and smooth endoplasmic reticulum was lost, while refeeding these rats with vitamin $\mathrm{E}$ resulted in a restoration of the normal distribution. These findings were interpreted as being suggestive of the possibility that Se, and particularly selenide, might have a role in the electron transfer functions associated with mitochondria and smooth endoplasmic reticulum. In view of the fact that mitochondria contain non-haem iron proteins (Beinert \& Lee, 1961) the active centres of which contain sulphide, the hypothesis was tentatively advanced (Caygill et al. 1971) that the selenide might form a part of the active centre of a class of non-haem Fe-selenide proteins.

(c) Membrane studies. A number of observations have been made that suggest that vitamin E might play a structural role in intracellular membranes. Thus, $\alpha-$ tocopherol functions specifically to prevent the increased haemolytic susceptibility to dialuric acid or hydrogen peroxide that can be demonstrated in erythrocytes derived from vitamin E-deficient rats (Rose \& Gyorgy, 1950). Furthermore, haemolysis by retinol added in vitro was inhibited by vitamin $\mathrm{E}$ (Lucy \& Dingle, 1964), and, of particular interest, by 6-O-acetyl- $\alpha$-tocopherol, squalene, phytol, phylloquinone and ubiquinone-30; 'classical' antioxidants such as hydroquinone and $N, N^{\prime}$-diphenyl-p-phenylenediamine were inactive. These findings were interpreted as suggesting that the protective function might be attributable to a steric function of the hydrocarbon side-chain rather than to any antioxidant function, and Lucy (1964) proposed that the liquid-like properties of the $\alpha$-tocopherol sidechain might play an important part in the stabilization of membrane structure in vivo.

(d) Hypothesis. The several observations mentioned above have been incorporated into a working hypothesis for the mode of action of vitamin $\mathrm{E}$ and Se (Lucy, 1972; Diplock \& Lucy, 1973). The idea that $\alpha$-tocopherol might stabilize membrane structure obtained considerable impetus when we found in our model-building studies that the possibility of a specific physico-chemical interaction could be demonstrated between the phytyl side-chain of $\alpha$-tocopherol and an arachidonyl chain located at the 2-position of the glyceryl moiety of a phospholipid. With the side-chain of $\alpha$-tocopherol located in the hydrophobic region of a membrane bilayer, the redox function would be expected to lie in a more polar region where its antioxidant function would be directed toward oxidant-sensitive regions of membrane-associated proteins that contain selenide.

The existence of an arrangement in mitochondrial and endoplasmic reticulum membrane similar to that described above, and more fully in our publications (Lucy, 1972; Diplock \& Lucy, 1973), would be expected to have certain functional 
consequences: (I) the inhibition by $\alpha$-tocopherol of oxidative destruction of membrane PUFA; (2) a reduction in the permeability of biological membranes containing high levels of PUFA, upon the addition of $\alpha$-tocopherol and (3) functional disruption, in vitamin $\mathrm{E}$ deficiency, of membrane-associated enzymes or enzyme systems caused by peroxidation of lipids and by the derangement of membrane structure consequent upon the uncontrolled 'activation' of membrane-bound phospholipases in the manner we have postulated (Diplock \& Lucy, I973). Study of (I) has yielded controversial results; experiments on (2) are at present being undertaken; study of a membrane-associated enzyme system (3) which is associated with microsomal (smooth endoplasmic reticulum) electron transfer was therefore undertaken.

\section{Function of vitamin $E$ and $S e$ in rat liver microsomal drug metabolism}

(a) Phenobarbitone induction and electron transfer function. The observation that $\mathrm{Se}$ and selenide tended to become localized in the liver smooth endoplasmic reticulum (Caygill et al. 197I) was extended in an examination of the possibility that phenobarbitone, an inducer of the microsomal drug-metabolizing enzyme system (Estabrook \& Cohen, I969) might also effect the incorporation of Se. The results (Caygill, Diplock \& Jeffery, I973) showed that, in normal rats, phenobarbitone treatment induced a large increase in the uptake of ${ }^{75} \mathrm{Se}$ and its conversion to ${ }^{75} \mathrm{Se}^{2-}$; when vitamin $\mathrm{E}$ was withdrawn from the diet this effect was no longer seen. The levels of the haemoproteins cytochrome $b_{5}$ and $P-45^{\circ}$ were unaltered in vitamin $\mathrm{E}$ deficiency, and their induction with phenobarbitone was normal; the reduction of the haemoproteins by $\mathrm{NADH}$ and NADPH was also normal (Caygill et al. 1973). The activities of the NADH- and NADPH-dependent flavoprotein reductases were also unchanged by the deficiency but the rate of oxidation of NADPH in the presence of aminopyrine was found to be slower in a microsomal fraction derived from vitamin E-deficient rats (Giasuddin, Caygill, Diplock \& Jeffery, 1974).

(b) Non-haem $\mathrm{Fe}$ as a component of the system. Investigation of the possibility that rat liver microsomal fraction might contain a non-haem Fe protein was made by Miyake, Mason \& Landgraf ( 1967 ) who, using an electron spin resonance technique, failed to demonstrate the presence of non-haem Fe; Hoffström, Ellin, Orrenius, Bäckström \& Ehrenberg (I972), however, detected non-haem Fe in kidney microsomes using a similar technique. The possibility that an $\mathrm{Fe}$-selenide non-haem Fe protein might exist in the liver microsomal system would explain the results of Miyake et al. (1967), since the extreme lability of such a protein would make it unlikely that it would be detected by the methods they used. We have studied the non-haem Fe content of liver microsomes, derived from rats given various dietary treatments, in the presence and absence of antioxidants added in vitro (Caygill $\&$ Diplock, 1973). It was found that, when antioxidants were present in vitro, nonhaem Fe could be detected; when the antioxidants were removed, the non-haem Fe disappeared. In vitamin $\mathrm{E}$ deficiency the oxidant-labile non-haem $\mathrm{Fe}$ was replaced by a more stable form and the oxidant-labile form was only found when Se was $33(3) 9$ 
present in the diet as well as vitamin E. We concluded that an Fe-selenide protein may be a constituent of the normal liver microsomal electron transfer system, the oxidative degradation of which is prevented by vitamin $\mathrm{E}$.

(c) Metabolism of aminopyrine. Evidence that the oxidative demethylation of certain drugs was impaired in vitamin E deficiency has been provided by Carpenter ( 1967 , $1968,1972)$. In view of the fact that drug demethylation is a primary function of the microsomal system we have studied the role of vitamin $E$ and $\mathrm{Se}$ in the demethylation of aminopyrine (Giasuddin et al. 1974). Our results confirm and extend those of Carpenter ( 1967, 1968, 1972); aminopyrine demethylation was found to be impaired in liver microsomes derived from vitamin E-deficient rats and this impairment was shown to be unaffected by the addition of antioxidants in vitro, indicating that the phenomenon was due to a pre-existing biochemical lesion in vivo. Detailed kinetic studies revealed that, in vitamin E deficiency, the apparent $K_{\mathrm{m}}$ of the enzyme system was consistently higher than in the supplemented controls, and the apparent $V_{\max }$ was unaffected. The sharp difference in apparent $K_{\mathrm{m}}$ was also noted when the rats were treated with two inducers of microsomal drug-metabolizing activity; the apparent $K_{\mathrm{m}}$ values observed were lower than those of the untreated rats, but those of the vitamin E-deficient animals were higher by a constant amount than those of the supplemented controls. When the role of Se was investigated, it was found that supplementation of vitamin E- and Sedeficient rats with either nutrient singly failed to restore the full demethylase activity of the liver microsomal fractions derived from them; only when both nutrients were supplied together was the full activity restored.

(d) Conclusions. At the present time, much circumstantial evidence exists that $\mathrm{Se}$ and vitamin $\mathrm{E}$ are involved together in the transfer of electrons from reduced pyridine nucleotides to oxygen in rat liver smooth endoplasmic reticulum. This may be summarized as follows: (1) the incorporation of Se and its conversion to selenide is vitamin E-dependent in smooth endoplasmic reticulum; (2) the processes involved in (I) are only stimulated by phenobarbitone in the presence of vitamin E; (3) the rate of NADPH oxidation during drug metabolism is lowered in microsomes from vitamin E-deficient rats; (4) oxidant-labile non-haem Fe may be demonstrated in microsomes from normal rats and its existence depends on dietary Se and vitamin E; (5) aminopyrine demethylation, which depends on the electron transfer function, is impaired in liver microsomes of vitamin E-deficient rats, and both vitamin $\mathrm{E}$ and Se are required for its restoration to normal. These observations are consistent with our working hypothesis (Diplock \& Lucy, 1973).

The possibility exists that these changes in electron transfer function are a direct consequence of oxidative destruction of the PUFA in the phospholipids of the membrane with which the electron transfer proteins are associated. This could be either by an enzymic mechanism (McCay, Poyer, Pfeifer, May \& Gilliam, 1971) or by direct oxidative attack. If $\alpha$-tocopherol functions in the manner we have suggested (Diplock \& Lucy, 1973) to promote membrane stability and compactness by physical means, then destruction of $\alpha$-tocopherol might not be seen as a corollary of peroxidative attack on unsaturated fatty acids. This could thus 
explain the failure of Green, Diplock, Bunyan, McHale \& Muthy (1967) to demonstrate an increased rate of destruction of ${ }^{14} \mathrm{C}$-labelled $\alpha$-tocopherol in rats given large amounts of PUFA. Furthermore, the possibility of accelerated breakdown of membrane-associated phospholipids by endogenous phospholipases in the absence of tocopherols must be considered (Diplock \& Lucy, 1973). The probable consequence of peroxidation or of increased phospholipase-induced membrane turnover would be that non-haem proteins, located in more polar regions of the membrane, would become susceptible to destruction. In these circumstances, selenide-Fe proteins, because of their sensitivity to oxidation, would be particularly vulnerable. The substitution of sulphide for selenide in these proteins that we have suggested (Caygill \& Diplock, I973) would be expected to have the consequence of a sharp change in the kinetics of reactions associated with the electron transfer chain, such as that we have observed in drug metabolism (Giasuddin et al. 1974).

\section{Summary}

Research on vitamin $\mathrm{E}$ and Se appears to be moving toward two important conclusions: first, that vitamin $\mathrm{E}$ has a function in promoting stability in biological membranes either by performing a role as a classical antioxidant, or by functioning in an enzymic system that prevents peroxidation of membrane lipids, or by performing a structural role in maintaining the integrity of membrane architecture; secondly, that Se plays a part in biological oxidation-reduction systems that, in mammals and birds, include glutathione peroxidase, a protein derived from lamb muscle and membrane-associated drug metabolism in rat liver. While the involvement of Se is only established with certainty in one of these systems, the nature of the participation of Se in the electron transfer events is not understood. The coming few years should see the elucidation of this problem and of the character of the interaction between Se and vitamin $\mathrm{E}$.

\section{REFERENCES}

Beinert, H. \& Lee, W. (I961). Biochem. biophys. Res. Commun. 5, 40.

Carpenter, M. P. (1967). Fedn Proc. Fedn Am. Socs exp. Biol. 26, 475 Abstr.

Carpenter, M. P. (1968). Fedn Proc. Fedn Am. Socs exp. Biol. 27, 677 Abstr.

Carpenter, M. P. (I972). Ann. N.Y. Acad. Sci. 203, 81.

Caygill, C. P. J. \& Diplock, A. T. (1973). FEBS Lett. 33, 172.

Caygill, C. P. J., Diplock, A. T. \& Jeffery, E. H. (r973). Biochem. F. 136, 85 I.

Caygill, C. P. J., Lucy, J. A. \& Diplock, A. T. (197I). Biochem. F. 125, 407.

Dam, H. (1953). Experientia 9 Suppl. 1, p. I95.

Diplock, A. T., Baum, H. \& Lucy, J. A. (1971), Biochem. F. 123, 721,

Diplock, A. T., Bunyan, J., McHale, D. \& Green, J. (1967). Br. F. Nutr. 21, Io3.

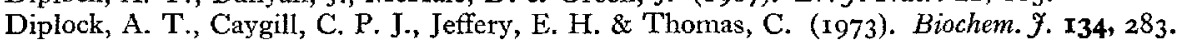

Diplock, A. T. \& Lucy, J. A. (1973). FEBS Lett. 29, 205.

Estabrook, R. W. \& Cohen, B. (1969). In Microsomes and Drug Oxidations p. 95 [J. B. Gillette, A. E. Conney, C. J. Cosmides, R. W. Estabrook, J. R. Fouts and G. J. Mannering, editors]. New York and London: Academic Press.

Flohé, L., Günzler, W. A. \& Schock, H. H. (1973). FEBS Lett. 32, 132.

Giasuddin, A. S. M., Caygill, C. P. J., Diplock, A. 'T. \& Jeffery, E. H. (I974). Biochem. F. (In the Press.)

Green, J. \& Bunyan, J. (1969). Nutr. Abstr. Rev. 39, 321.

Green, J., Diplock, A. T., Bunyan, J., McHale, D. \& Muthy, I. R. (I967). Br. F. Nutr. 21, 69.

Green, J., Diplock, A. T., Bunyan, J., Muthy, I. R. \& McHale, D. (1967). Br. F. Nutr. $21,497$. 
Hoekstra, W. G. (1974). In Trace Element Metabolism in Animals p. 6r [W. G. Hoekstra, J. W. Suttie, H. E. Ganther and W. Mertz, editors]. Baltimore, Maryland: University Park Press.

Hoffström, I., Ellin, A., Orrenius, S., Bäckström, D. \& Ehrenberg, A. (I972). Biochem. biophys. Res. Commun. 48,977 .

Horwitt, M. K. (196I). Borden's Rev. Nutr. Res. 22, I.

Karrer, P. (editor) (1962). Vitams Horm. 20, 373.

Lester, R. L. \& De Moss, J. A. (197т). F. Bact. 105, 1006.

Lucy, J. A. (1964). Biochem. F. 99, 57 P.

Lucy, J. A. (1972). Ann. N.Y. Acad. Sci. 203, 4.

Lucy, J. A. \& Dingle, J. T. (1964). Nature, Land. 204, 156.

McCay, P. B., Poyer, J. L., Pfeifer, P. M., May, H. E. \& Gilliam, J. M. (1971). Lipids 6, 297.

Mattill, H. A. ( 1927). Am. F. Physiol. 79, 305.

Mattill, H. A. \& Golumbic, C. (1942). F. Nutr. 23, 625.

Mills, G. C. (1959). F. biol. Chem. 234, $5 \circ 2$.

Miyake, Y., Mason, H. S. \& Landgraf, W. (1967). 7. biol. Chem. 242, 393.

Noguchi, T., Cantor, A. H. \& Scott, M. L. (I973), F. Nutr. xo3, I 502.

Pedersen, N. D., Whanger, P. D., Weswig, P. H. \& Muth, O. H. (I972). Bioinorg. Chem. 2, 33.

Rose, C. S. \& Gyorgy, P. (1950). Blood 5, ro6z.

Rotruck, J. T., Pope, A. L., Ganther, H. E., Swanson, A. B., Hafeman, D. G. \& Hoekstra, W. G. (1973). Science, N.Y. r79, 588.

Schwarz, K. (1951). Proc. Soc. exp. Biol. Med. 78, 852.

Shum, A. C. \& Murphy, J. C. (I972). F. Bact. rro, 447.

Smith, P. J., Tappel, A. L. \& Chow, C. K. (1974). Nature, Lond. 247, 393.

Tappel, A. L. (1 962 ). Vitams Horm. 20, 493.

Turner, D. C. \& Stadtman, T. C. (1973). Archs Biochem. Biophys. 154, 366.

Whanger, P. D., Pedersen, N. D. \& Weswig, P. H. (1973). Biochem. biophys. Res. Commun. 53, I031. 